\title{
Individual Moral Development and Moral Progress
}

\author{
Anders Schinkel ${ }^{1}$ • Doret J. de Ruyter ${ }^{1}$
}

Accepted: 29 May 2016 / Published online: 13 June 2016

(C) The Author(s) 2016. This article is published with open access at Springerlink.com

\begin{abstract}
At first glance, one of the most obvious places to look for moral progress is in individuals, in particular in moral development from childhood to adulthood. In fact, that moral progress is possible is a foundational assumption of moral education. Beyond the general agreement that moral progress is not only possible but even a common feature of human development things become blurry, however. For what do we mean by 'progress'? And what constitutes moral progress? Does the idea of individual moral progress presuppose a predetermined end or goal of moral education and development, or not? In this article we analyze the concept of moral progress to shed light on the psychology of moral development and vice versa; these analyses are found to be mutually supportive. We suggest that: moral progress should be conceived of as development that is evaluated positively on the basis of relatively stable moral criteria that are the fruit and the subject of an ongoing conversation; moral progress does not imply the idea of an end-state; individual moral progress is best conceived of as the development of various components of moral functioning and their robust integration in a person's identity; both children and adults can progress morally - even though we would probably not speak in terms of progress in the case of children - but adults' moral progress is both more hard-won and to a greater extent a personal project rather than a collective effort.
\end{abstract}

Keywords Moral progress $\cdot$ Moral development $\cdot$ Moral psychology $\cdot$ Kohlberg $\cdot$ Blasi $\cdot$ Children

\section{Introduction}

At first glance, one of the most obvious places to look for moral progress is in individuals, in particular in moral development from childhood to adulthood. In fact, that moral progress is possible is a foundational assumption of moral education. Parents and teachers would not teach children that they should not hurt their pet, be kind to their siblings or explain why they should not cheat at an exam if they did not believe that this would contribute to the moral

Anders Schinkel

a.schinkel@vu.nl

1 Faculty of Behavioural and Movement Sciences, VU University Amsterdam, Van der Boechorstraat 1, 1081 BT Amsterdam, The Netherlands 
improvement of children. Beyond the general agreement that moral progress is not only possible but even a common feature of human development things become blurry, however. For what do we mean by 'progress'? And what constitutes moral progress? Does the idea of individual moral progress presuppose a predetermined end or goal of moral education and development, or not? Is the kind of progress we might make as adults of the same kind as that we might make in our growth to adulthood, or is a different notion of progress at play here? In this paper we approach these questions through analyses of, firstly, the concept of moral progress (Section 2) and secondly, the psychology of moral development (Section 3). Thus, we use the literature on the concept of moral progress to shed light on the psychology of moral development and vice versa; and we will see that both analyses mutually support each other. Section 4 will be devoted to a comparison of the moral progress of children and that of adults. We will end with a summary of our findings and some concluding remarks.

\section{The Concept of Moral Progress}

To clarify the notion of moral progress we will distinguish (1) a strong and a weak concept, (2) different levels on which progress may take place, and (3) formal and substantial criteria of moral progress.

\subsection{The Weak and the Strong Concept of Progress}

The core of the concept of progress is 'things getting better'. But is there more to it than that? In everyday life we often speak of progress when things at a certain time are better than they were at a previous time. For instance, a parent may look at a child's school report, notice that on average the child has received higher grades and say that the child has made progress. In the literature the concept of progress is sometimes explained this way, as simply a combination of a descriptive element (the observed change) and a normative or evaluative element (the evaluation of the observed change) (Macklin 1977: 372-373). More often, however, a further element is added to the concept of progress. Perhaps the child was lucky to get better grades; the exam questions just happened to fall right. To be able to speak of progress it seems we need to know more about the background of the change, and have reason to think the observed 'trend' will consolidate itself, will indeed be a trend.

The distinction introduced above is that between a weak and a strong concept of progress. The former defines progress simply as positively evaluated change; the latter adds a condition, which we may call (indicating its extreme form) irreversibility. This formal criterion can be found in philosophy of history, as a thesis on the progress of civilization or mankind (see Bury 1987: 2; Van Doren 1967: 3; Nisbet 1980: 4-5), but also in developmental psychology, particularly in Kohlberg's work (Kohlberg 1984).

We see the weak and the strong concept as the extremes of a spectrum. Complete irreversibility is unthinkable: any (moral) progress made by individuals or societies can also be undone. Think for example of people who come under the spell of an evil leader or societies that harden against non-indigenous citizens. The weak concept is too thin, however, too superficial: to be able to speak of progress the causes of the change need to be more than incidental, they need to have firm roots in the subject of progress, so that we can be reasonably confident in the stability and sustainability of the change. A slightly stronger concept would recognize these claims, but refrain from making any claims about the (im)possibility of 
regress. The change could be the result of intentional effort, yet be completely reversible in case the effort was aborted. For instance, a child might make progress on the piano, but fall back again due to lack of practice. ${ }^{1}$ This is indeed a normal manner of speaking in everyday life. However, when it comes to considered judgements of progress, it still seems too weak - it misses something important, namely the idea that the observed change for the better is not superficial, but the external expression of an internal or underlying change. Hence, we will speak of progress only in cases of positive change that cannot be wholly undone without difficulty. In other words: progress is positive development, where development means durable, non-superficial, change. Someone who, through serious practice, makes progress at the piano, may fall back through lack of practice, but it is unlikely that she will return to her pre-practice level, unless she does not play the piano for a substantial period of time; furthermore, the fact that she will most likely need less practice than the first time to regain her previous top level, suggests that an 'internal' change has indeed taken place. ${ }^{2}$

This concept leaves room for stronger and weaker conceptions of progress - depending on where one places the (formal or substantial) threshold for speaking of progress - and for stronger and weaker forms or types of progress. In this paper we will make use of the second distinction.

A helpful image here is that of a stone that is being rolled up a hill. In one (extreme) case the weak concept of progress - the slope is even and steep; as soon as the upward force exercised on the stone slackens a bit too much, the stone rolls all the way back down again. In the other (extreme) case - the strong concept of progress - the slope is not even, but characterized by hollow ridges; the stone is pushed up the hill for a bit, to rest on the next ridge, and so on. It would take an effort to dislodge it from such a ridge and make it roll down again, and it would not roll all the way back down, but only to the next ridge. This latter image can be tweaked in many ways: the ridges may be close together or further apart, and the edges of the ridges may be higher or lower, so that it would require more or less effort to dislodge the stone. The image also makes clear that absolute irreversibility is impossible: landslides caused by erosion or some other cause can occur even on the most stable of mountains. To be sure, the image we use here should not be taken to suggest that all progress is necessarily intentional, the result of a conscious purposive effort. Especially in the case of young children this is seldom the case. We will return to this in Section 4.

\subsection{Progress as Improvement and Progress as Development towards an End-State}

According to one conception progress is nothing more than (relatively durable or stable) improvement, whereas another, teleological, conception emphasizes the idea of a final goal or end-state which is (to be) approached or attained (Godlovitch 1998). ${ }^{3}$ Whereas the teleological

\footnotetext{
${ }^{1}$ We thank an anonymous reviewer for offering this suggestion, including the example.

2 It seems plausible that this criterion - that the concept of 'progress' only applies in case of positive change that cannot be undone without difficulty - applies even more strongly in the case of moral progress, given the nature of the change involved (for which see Section 3). It seems plausible, for instance, that progress in moral convictions or moral sensitivity can only be undone with difficulty, through force of (bad) reasons or circumstances. An important difference between piano playing and moral functioning is that whereas one can avoid practicing the piano, one cannot avoid moral functioning. Insofar as one has made real - as opposed to merely apparent - progress, therefore, it is difficult to see how this can be lost merely as a result of 'lack of practice'.

3 Two remarks are called for here: 1) For Godlovitch the notion of teleological progress implies nothing about the (positive) value of the change in question; we, however, view the teleological model as a model of progress. 2) Godlovitch also distinguishes a third kind of progress, which he calls 'raw progress', as in 'charting the progress of X'. Because this concerns observed change or movement unaccompanied by evaluation we will leave it aside.
} 
conception, so Godlovitch argues, assumes that there is a fixed standard (the final goal or endstate) by which progress must be measured, according to the other conception we can speak of improvement as soon as a situation is in some respect preferable over an earlier situation. According to the conception of progress as improvement, Godlovitch claims, the criterion of progress will be changeable and depend on the wider context and the demands this makes; it will be 'relative to certain operative pressures at a time' and 'to some interest' (ibid.: 275). The criterion has some stability - otherwise the situations could not be compared - but because the 'operative pressures (...) themselves change' the stability or constancy will be relative and temporary (idem). In our view it is better to separate these issues (improvement v. end-state and changeable v. fixed standard); they do not necessarily coincide. We will address the question of the stability of the standard in 2.4 .

Sequences of events are said, by Godlovitch, to be 'strongly teleological' when we know what a certain development will culminate in and should culminate in, as is the case (roughly), for instance, with the development of a foetus. They are said to be weakly teleological when we do not have that knowledge but can still with some justification treat the sequence of events under consideration as if it were culminative. The climax hypothesis in ecology, which states that ecosystems tend towards a stable state (with a certain mixture of flora and fauna), would be an example of that (ibid.: 274). ${ }^{4}$

The distinction between 'improvement' and teleological progress can be nuanced and qualified, but there is a real difference at stake: in the former case there is no developed 'picture' of an end-state; instead criteria are used that are at most pieces of such a picture. ${ }^{5}$ This means there is much room for different directions of development, and development need not be aimed at a clearly demarcated endpoint. In practice - not least the practices of childrearing and education - this seems to be the default situation.

Godlovitch sees moral progress as a hybrid of improvement and global (which for him means: at the level of species, entire civilizations, or whole human domains, such as art, science, and politics), weakly teleological progress; his focus is on the societal level (see below). He rightly points out that we cannot say what the goal of (collective) moral development is as long as our knowledge is 'incomplete' (which we take to be necessarily the case). Neither the conception of individual progress we defend here, nor our conception(s) of collective progress, assume that there is one fixed final goal. To be able to speak of moral progress we need no more than a (relatively) stable standard; and there may be more than one standard. What kind of standard(s) we need and have at our disposal is the subject of the 2.4 .

\subsection{Individual and Collective Moral Progress}

Very roughly, (moral) progress may take place on two levels: that of individuals, and that of collectives. Individual moral progress refers to the moral-psychological development of an individual; when an individual develops in a desirable direction in the moral domain (so undergoes durable positive change) this constitutes moral progress.

\footnotetext{
${ }^{4}$ Godlovitch also distinguishes between local and global (in his terms 'broad) teleological progress, but in a somewhat different way than we have done.

${ }^{5}$ Cf. Amartya Sen's (2009) critique of John Rawls: we do not require an ideal picture of a just society in order to be able to make progress in this area.
} 
Collective moral progress is a vaguer notion. It might refer to biologically based progress of the human species or human populations, to cultural-historically grounded progress of civilizations or societies or again humanity as a whole, or a combination of both. It might also indicate progress of smaller collectives or organizations. It might be helpful to distinguish two interpretations of collective moral progress: 1) Generational progress. This is progress of 'groups' of people, measured in terms of the average moral 'quality' of the individuals of a certain generation. 'Group' has no substantive meaning here; it denotes a collection of individuals - e.g. all British citizens born in the sixties. 2) Societal progress, which is assessed on both an institutional (e.g. laws) and a practical level (e.g. the moral quality of people's conversation in (social) media). We will not elaborate on this here, however, since our focus will be on individual moral progress.

A further important distinction is that between local and global progress. The former denotes progress in a limited number of (sub)domains of moral concern or aspects of moral functioning, whereas the latter indicates progress across (virtually) all (sub)domains of moral concern and aspects of moral functioning (cf. Moody-Adams 1999: 169). Local progress in aspects of moral functioning occurs, for instance, when an individual's moral reasoning improves, while his moral sensitivity, motivation, and affect more generally remain the same. Progress that is local in terms of domains of moral concern may occur when a society becomes more sensitive to issues of discrimination, but remains highly unequal socio-economically, or, to give another example, when an individual's commitment to ethical consumption grows stronger while the moral quality of his dealings with others in the personal sphere remains the same. Just as progress may be 'weaker' or 'stronger', it can also be more or less local or global.

\subsection{Formal and Substantial Criteria of Progress}

The weak and the strong concept of progress use different formal criteria to define progress; for example, according to the strong concept a necessary condition for a change to be able to count as progress is that the change is irreversible. But inherent in both concepts of progress and in any conception of progress is the notion of things getting better, and this implies the use of substantial criteria. Are there such criteria available to us when it comes to moral progress, and if so, what kind of criteria are they?

As explained above, Godlovitch (1998: 275) distinguishes teleological progress - progress towards an end state - from progress as improvement (without reference to a final goal), and ties these to the distinction between using a stable criterion and using changeable criteria, norms that are constant so long as certain 'interests' or 'operative pressures' remain in place. We do not see progress as necessarily bound up with the idea of an end state, but neither do we favour the use of wholly relative criteria. The problem with the latter is that a historical or developmental episode may be labelled as 'progress' at one point, from one perspective, and 'regress' at another time, from a different perspective; this renders talk of moral progress rather empty. A third option seems to be to use stable criteria that are not wholly relative to current interests (without positing an end state); a set of moral principles by which we measure progress. Macklin (1977) proposes two such principles: 'the principle of humaneness' and 'the principle of humanity' (which concerns respect for human dignity). Roth (2012: 385) sees this as a variant of the utopian model (her name for teleological conceptions), which she rejects because our standards or criteria are also subject to change, and she does not believe there is a final, unchanging standard behind all this. Her own Deweyan approach sees progress in terms of increasing problem-solving capacity. Roth (2012: 391) uses the term 'problem' to indicate 
"a certain sort of experience of ourselves, our beliefs, our values, and the world. Problems arise when we experience trouble, difficulty, or conflict - when there is disharmony amongst our empirical beliefs, our values, and our experience of living." People approach any problem from somewhere - their background values - but even these can be revised (ibid.: 396). Progress is measured by asking: did the problem we start out with disappear or diminish? Has the number of problems we are faced with decreased?

Michele Moody-Adams also points out that in practice - and justifiedly - we do not measure progress according to some fully specified final goal that our views and actions ought to tend towards, but that we observe moral progress locally, in limited 'domains of concern' (1999: 169). Progress in moral convictions, for instance, is a matter of increasing understanding of the 'semantic depth' of moral concepts: we gain a sharper view of the richness and the scope of a concept, and come to see why a new interpretation of a moral concept does more justice to moral experience (idem; she refers to Platts 1988 here). According to Moody-Adams we have no immutable moral principles at our disposal, but we do have fairly reliable, context-dependent signs of moral progress. As an example she suggests that whenever a proposed institution or practice can be upheld without extreme violence and with minimal compulsion it will often be the case that its realisation points to moral progress. When a certain society does not notice the evil of slavery, this has to do, in Moody-Adams' view, with a refusal to critically reflect on its own practices. Thus, Moody-Adams comes closer than Roth to arguing for universal and unchanging standards.

As mentioned, in our view the plausibility of speaking of (moral) progress is undermined when criteria of progress are (too) changeable and relative. All progress would then be 'progress' - progress for as long as we use these criteria. Roth's proposal to use a formal criterion instead of a substantive one also fails, however. To begin with, a (moral) 'problem' can be anything that is perceived as such by some people. Roth gives the example of teenage pregnancy, saying that '[p]resumably, most Americans would agree that 'teen pregnancy' is a problem' (2012: 392). Maybe, but what about homosexuality, for instance? Is that a moral problem? It was certainly perceived as such by most people in the past, and many people today believe it is morally problematic; and yet the problem may lie not with homosexuality as such but with the moral views of those who condemn it. And when does a problem count as solved? When people stop perceiving it as a problem? If the example is homosexuality we are inclined to say yes, but others would disagree, and Roth cannot offer a way out without abandoning pragmatism in favour of a more objectivist approach. The problem-solving conception of moral progress begs the question if it offers no independent criteria by which to judge whether a problem has been solved or not.

What we are saying here, then, is that a purely constructivist approach to moral progress is untenable; does that mean we are committed to realism about moral progress? Jamieson (2002: 321) describes the problem as follows: moral realism respects our intuitions about moral progress but conflicts with our metaphysical sensibilities, because these have a problem with 'facts' that are intrinsically motivating. The constructivist perspective, on the other hand, may be able to deal with the specific nature of moral 'facts', but flies in the face of strong intuitions about real cases of moral progress. There is no need to choose between either extreme, however (and neither does Jamieson, who develops a kind of pragmatism with objectivist elements). Roth's pragmatism aims at an intermediate position but in our view her position collapses into constructivism (or relativism). Wilson (2010) also seeks an intermediate 
position: 'moral progress without moral realism', according to which moral beliefs can be true or false, even though there is no such thing as an independent moral reality. Moral truths, like scientific truths, are the outcome of specific processes of theory change. What Wilson explicitly rejects is robust moral realism (as defended, for instance, by Railton [1986] and Shafer-Landau [2005]), which entails a commitment to the metaphysical claim that the truth of moral claims depends on their correspondence with real moral facts and properties that are metaphysically on a par with non-moral facts and properties. But Wilson is willing to claim truth status for certain moral beliefs, and the opposite for others, such as the belief that homosexuality is unacceptable (110). Thus, she does seem to embrace a form of objectivism similar to that accepted by minimal moral realism, which (unlike Wilson) remains agnostic on the metaphysical issue but holds on to the possibility of objective moral truth. ${ }^{6}$ Whether or not objectivism without realism is ultimately defensible, it is objectivism we need in order to be able to speak sensibly of moral progress. Of the positions available in the literature on moral progress, Moody-Adams' view seems to us best suited to do justice both to moral objectivism and the contextual nature of morality.

With Moody-Adams (1999) we suggest that moral progress be measured by means of ongoing interpretations of moral experience and moral concepts, which we assume are characterized by certain inescapable aspects that we need to do justice to - the kind of aspects Macklin points to (in a way, to be sure, coloured by the dominant ethical traditions of her time). There is a sense in which experience per se has a moral character, if 'experience' is understood as 'something speaking to us', as our 'being addressed by something' that calls for interpretation (Van Tongeren 1994: 203). It is part of being human that we seek and are receptive to meaning, rather than indifferent to it. But moral experience is also moral in a more familiar sense: it is experience in which "we are summoned or obliged to commit ourselves to, or continue in, a certain way of acting or relating, or praxis, which is at the same time understood as being part of real or good human life" (ibid.: 204). Although our answer to such an address is always contextual and dependent on an interest on our part, it is at the same time still a response to a normative demand. Social contexts are highly changeable, a fact with obvious implications for which moral considerations apply in various circumstances, and for how we might morally assess past practices. But the moral experience of people throughout history is recognisable for us as moral experience; and this allows us to enter into a dialogue about decreasing or increasing moral sensitivity and insight. In a similar vein Weischedel (1967: 89) suggests that the differing moral ideals of different periods may be seen as varying answers to the same basic question, which he sees as the question, or task, of balancing two sides of human nature: our individuality and our social nature - for without others we could not be ourselves (ibid.: 91).

We will not defend a particular substantive conception of moral progress here; what follows is predicated on the assumption that substantive moral progress - in a stronger sense than Roth's - is possible, i.e. that some ways of being and doing are morally better than others and that it is possible to develop such that one becomes morally better. Our description of individual moral progress will be largely formal, and in so far as it involves substantial criteria these will remain fairly abstract.

\footnotetext{
${ }^{6}$ The distinction between robust and minimal moral realism was coined by Nicholas Sturgeon (1985).
} 


\section{Individual Moral Development}

Moral psychologists study the development of children and adolescents in the moral domain. Earlier we used the term 'development' to refer to durable, non-superficial change, regardless of whether this change is deemed to be 'positive' or 'negative'. In psychology, however - and above all in moral psychology - the term 'development' is used exclusively to denote positive change with a durable, non-superficial character. 'Development', in this field, is not a neutral term, but is equivalent with 'progress'. Claims about development therefore presuppose normative principles. All work in this area is based, either explicitly or implicitly, on a theory of moral progress that is connected with ideas about the characteristics of the morally mature and the development towards moral maturity, even if it (only) concerns an aspect (cognition for instance) of moral development. There are two ways in which this may be the case. One possibility is that psychologists, with or without being aware of it, subscribe to such a theory and the meta-ethical and normative-ethical commitments it implies. It is quite clear that when Lawrence Kohlberg, Martin Hoffman, William Damon, August Blasi, but also people like John Gibbs and Lawrence Walker - to name a few important authors in this area not discussed below - write about moral development they are not distancing themselves from the (normative) concepts of morality and moral maturity involved, but are instead quite committed to them. They are concerned to discover and do justice to what morality is and how it is or becomes anchored in human psychology, rather than work on the basis of an assumed or taken-for-granted hypothetical. Just to illustrate: Gibbs (2014) explicitly sets out to develop a theory of morality; Matsuba and Walker (2005) begin their paper as follows: "Within the last century, the world has witnessed some of the most heinous crimes against humanity. Yet, even in our darkest hours there were glimpses of hope that the world could be a kinder and gentler place; a place where the poor and dying could find love, acceptance, and dignity; and where all people are treated equal."

Another, currently perhaps more favoured option, is to adopt such a theory - or, more loosely, the common understanding of morality prevalent in a certain social group at a certain time - for the purposes of research without subscribing to it, i.e. while remaining agnostic about its meta-ethical and normative claims. Grazyna Kochanska, for instance, who writes about conscience as 'an inner guiding system responsible for the gradual emergence and maintenance of of self-regulation' (Kochanska and Aksan 2006: 1587) tries to avoid normative or meta-ethical commitments. Baillargeon et al. (2014), to give another example, employ an evolutionary understanding of (infant) 'sociomoral reasoning' that seems to be based on an implicit agreement about what comes under this heading, without however implying metaethical or normative commitments in any stronger sense. And Kagan (2008), being "concerned primarily with universals in the development of morality" (ibid.: 308) similarly avoids particular meta-ethical and normative commitments. It is important to note, however, that the absence of meta-ethical and normative-ethical commitments does not entail the absence of assumptions about the moral domain, moral maturity, and so on; they are still necessary in order to study moral development, even if they are only accepted as hypotheticals. Moreover, authors may be more or less explicit about their assumptions in various publications. For instance, Gil Diesendruck and Avi Benozio, who have researched bias and prosocial behaviour towards ingroup and outgroup members, are silent on their normative views in the one (Benozio and Diesendruck 2015), but end on an explicitly normative note in the other: "One of the implications of the above portrayal of children to educators is that, if we leave children to figure out the social world on their own, they might end up developing fairly 
discriminatory and biased dispositions. In other words, educators need to actively engage in curbing children's predisposed biases" (Diesendruck and Benozio 2015:4).

Either way, the study of moral development presupposes some demarcation of the moral domain, some view of what it means to be morally mature, and some conception of development.

The study of moral development presupposes a description of the moral domain, because if we cannot distinguish the moral from the non-moral, we cannot make any claims about moral development. Moral psychologists therefore need to adopt a meta-ethical position with regard to the nature of the moral. Secondly, it presupposes a characterization of the moral adult or the morally mature person, as someone who has developed in the moral domain towards a level that we normally expect adults to attain. That means that moral psychologists also need to employ a normative-ethical theory, from which criteria can be derived to judge what is morally good or desirable. Thirdly, the concept of development needs to be fleshed out. Psychologists can be categorized according to their answers to two questions in this regard, namely the question whether development is linear, and the question whether there is a universal developmental pattern. Answers to these questions are backed up by logical as well as empirical arguments. That moral development can be characterized as 'irreversible' (in the sense that it is a strong form of progress) is generally accepted by moral psychologists.

\subsection{Kohlberg's Theory of Moral Development}

Moral development, in Kohlberg's view, is the development of moral reasoning ability. He famously distinguished six universal developmental stages with a fixed, logically and empirically necessary order among them. Progression through these stages is held to be irreversible. The final stage - the goal of moral development - is that of the just person, someone who autonomously subscribes to and acts in accordance with the principle of justice.

The reasons why Kohlberg focussed on moral reasoning and judgement were varied. First of all, he described the moral domain as situations characterized by conflicts of interest that call for an impartial solution (see Lapsley 1996: 129). A person who is able to weigh interests in an adequate, impartial manner is someone who does justice to other people. For Kohlberg, being able to do justice to others is what most strongly characterizes the moral adult. This shows us - and this is the second reason for his focus on reasoning - how strongly Kohlberg was influenced by Kant's deontological moral theory (which meant that he rejected utilitarianism). Empathic abilities that enable people to put themselves in other people's shoes are, in the end, subsidiary. The only thing that is morally relevant about our actions is the reasoning behind it. 'Doing the right thing' means: doing whatever you do for the right reasons, reasons that are universalizable. Thirdly, Kohlberg held an internalist view of the relation between thinking and acting; he assumed, especially in his later work, that the combination of a moral judgement (that a certain moral rule applies in a certain way in the situation at hand) and a responsibility judgement (specifying whose responsibility it is to act; a judgement that in higher stages would coincide with the moral judgement) would automatically lead to moral action (cf. Bergman 2002).

To sum up: Kohlberg describes moral progress as irreversible improvement of moral reasoning. Progress continues until only reasons are used that are really relevant: reasons relating to the universalizability of the (proposed) action. A person who undergoes this development and is, in the end, only motivated by truly moral considerations has at the same time become autonomous, i.e. he is not driven by emotions, nor determined by conventions of 
his society or tradition. In the past decennia Kohlberg's theory - and with it his conception of moral progress - has drawn increasing criticism. Psychologists have defended alternative theories of moral development, which differ from Kohlberg's in their view of the moral domain, moral maturity, and development.

\subsection{A Broader Conception of the Moral Domain}

The first point of critique is that Kohlberg's description of the moral domain is too narrow, and offers a too restricted conception of individual moral progress. There is more to morality than justice, and there is more to justice than resolving conflicts of interest impartially. Furthermore, we can conceive of types of moral exemplariness that do not obviously resemble the Kohlbergian stage six. Think of Mother Theresa, for instance, whose motives and actions should be described in terms of care for others and concern for their well-being.

A more expansive view of the moral domain can be found in the work of Hoffman (2000) and Eisenberg (1992). Hoffman and Eisenberg believe that morality is not primarily about justice but also or even foremost about beneficence, doing good for others, also in situations where this does not serve one's self-interest - in other words about prosocial behaviour. Furthermore, besides cognition they see emotions as essential components of morality. They therefore study the development of empathy and sympathy. Hoffman distinguishes five stages in the development of empathy. Progress through these stages is driven mostly by cognitive development, by the ability to distinguish self and other and to take another person's perspective in such a way that one is increasingly capable of meeting others' needs. Cognitive abilities seem to play a larger role in Hoffman's theory than emotions do in Kohlberg's. The idea that moral emotions are an essential characteristic of the moral person is, in our view, an improvement on Kohlberg's conception. From a psychological point of view they play an important part in moral development and moral motivation; from a moral perspective, an action that is motivated purely by an intellectual sense of duty seems to us less praiseworthy than action that is (also) characterized by emotional concern and authentic interest (see also Marples 2014).

\subsection{A more Comprehensive Characterization of Moral Maturity}

Kohlberg's internalistic view that a person's level of moral reasoning will necessarily lead to a certain level of moral behaviour has been proven to be untenable. Moral psychologists have convincingly shown (as moral philosophers have done on theoretical grounds as well, it should be added) that moral behaviour is an 'exceedingly complex phenomenon' (Rest in Bergman 2002: 110) for which a moral person not only needs moral reasoning skills, but also moral emotions and moral motivation. To become good moral persons children have to learn and internalise a variety of qualities. Moreover, while these moral aspects can be theoretically distinguished, and while people can be better or worse in either one of them, characteristic of a good moral person is that these aspects are integrated into a coherent whole and part of a person's self-perception.

In moral psychology (broadly conceived, including philosophical moral psychology) we find two types of theory in which this integration is studied. On the one hand there is the research on moral identity development, instigated by Blasi (1984). Phrased in various ways, theories on moral identity argue that people are more likely to act morally if moral considerations, and these might be judgements, emotions or ideals, are better integrated with other 
aspects of people's identity and/or more central to the person's perception/narrative/conception of herself (see Bergman 2002). On the other hand there are various theories on character development, for instance positive psychology (e.g. Peterson 2006) and virtue ethics (see for instance Carr and Steutel 1999). These theories entail different views on development and its preconditions, but they all suggest that the idea of the development of a moral identity can also be related to virtue. Moral identity can be described as the moral virtues and values that are characteristic of people (both in their own eyes and those of others), in combination with people's narratives about who they wish or hope to be. Thus, as we take it, a person's moral identity is not confined to the moral traits or values the person actually has, but may also include a conception or an image of an ideal moral self (e.g. Blasi 1984, 1993; Hardy and Carlo 2005). This aspect of moral identity may be a special source of moral behaviour and dispositions (see for instance Rorty and Wong 1993) and add to the robustness of one's morality: one wants to be a moral person who contributes to the fairness of society. Importantly, both types of theory stress that moral development is a lifelong project. Moral integration, as Blasi sees it, is not fully achieved with the transition from childhood to adulthood; and the same goes for complete and perfect virtuousness (see for instance Sanderse 2012).

In Ann Colby and William Damon's work (1992), integration of self and morality is explained in terms also of the increasing centrality of morality in a person's identity. In our view this is not and need not be the aim of moral development in general, and is not the only way to interpret moral integration. Morality does not have to constitute the core of one's identity (although it cannot be completely peripheral), but it does have to be integrated with other aspects of one's identity (see 3.5 ).

\subsection{A more Realistic Conception of Moral Development}

Finally, the idea that moral development proceeds through stages, as Kohlberg proposed, can be found in many theories of moral development. Hoffman describes stages in the development of empathy. Gertrud Nunner-Winkler does so for the development of moral motivation. Rest distinguishes stages in the development of various components of moral functioning. Development need not be linear, however. Nunner-Winkler, for instance, describes temporary declines in moral motivation during the development to adulthood (2007: 142). And Larry Nucci and Elliot Turiel (2009) found evidence in their research for differences between cognitive and moral development. In the latter there seem to be transitional phases in which children seem to regress. They speak of a 'U-shaped pattern' that occurs during adolescence. Because older children and younger adolescents can process more information than younger children and encounter more diverse situations, they will need some time to reorient themselves morally. Their moral judgements can therefore be more variable. In terms of the image of the stone being rolled up the hill we used earlier: there will be periods of stability and even of seeming regress, and sometimes a higher goal can only be reached via an indirect route.

\subsection{Evaluation}

This brief venture into the field of moral psychology yields three insights. Firstly the observation that individual moral progress entails the development of different aspects or components of moral functioning across various domains of moral concern (such as interpersonal morality and more abstract issues of justice). The less consistent the progress across these 
components and domains is, the more local moral progress is. For most of us moral progress is not entirely global, but to some extent patchy. The second insight, therefore, concerns the importance of integration of the various components of moral functioning (as they function in the various domains of moral concern) both with each other and in a person's identity and selfconcept. The more a person is able to construct a coherent whole out of the moral and nonmoral aspects of her identity, and the more robust her identity is, the more morally developed she is. That does not mean that the moral dimension of her identity needs to become increasingly central, as Colby and Damon have suggested. In our view, moral development primarily concerns the degree of robustness of a person's moral identity, not its centrality. Morality should occupy a fitting place (that cannot be wholly peripheral), but it does not have to dominate all other domains of life. Moral development need not culminate in moral exemplariness or sainthood, but only in moral solidity. The third insight is that in the moral domain people can develop in different directions, towards different forms of moral maturity or even exemplariness - not just along the lines of 'care' and 'justice' (that have been unnecessarily strongly opposed), but also in the degree to which and the manner in which they are touched by specific (kinds of) moral issues.

A difficult question, of course, is what counts as a 'fitting' place for morality. At issue here is not the discussion between those who see 'being a self [as] inseparable from existing in a space of moral issues' (Taylor 1989, cited in Lapsley 2008) and those for whom morality is relatively separate from the rest of the personality, but rather the question how much weight should be given to moral considerations and moral qualities as opposed to other considerations and other valuable qualities - an issue also raised, famously, by Bernard Williams (1981, 1985 ) in terms of the distinction between the moral and the ethical. ${ }^{7}$ We cannot give more than a tentative suggestion of an answer here. Both objective and subjective criteria come into play. Objectively, morality has a fitting place in a person's identity when she only rarely gives precedence to non-moral matters over important moral ones. 'Important' now calls for explanation, that is best given in the form of an example. When someone has the disposition not to fulfil explicitly made promises whenever he does not feel like fulfilling the promise, morality occupies a small place - too small a place - in his identity. Fitting would be to be disposed to fulfil such promises. But one or two exceptions to such a disposition, on the other hand, would not mean that morality has no fitting place in a person's identity.

Why should we settle for a 'fitting place'? Why would increasing robustness of the moral dimension of a person's identity be the goal of moral development and an adequate view of individual moral progress, rather than increasing centrality of the moral element? When morality has a fitting and robustly anchored place in a person's identity, the necessary condition for progress is met that the change needs to be durable and non-superficial. Nothing is thereby said about the contents of moral identity. These can continue to develop, for instance through experience and increased understanding. When both the contents and the robustness of a person's moral identity are evaluated positively, we also know enough to be able to speak of progress. But would increasing centrality of the moral element not make for more progress?

\footnotetext{
${ }^{7}$ Other important reference points here are the utilitarian Singer (1972), who defended a notoriously demanding view of our moral obligations, and Richard Hare $(1952,1981)$, with his interesting mix of utilitarian and Kantian ethics, who saw it as part of the way we think about morality that moral considerations always 'override' other considerations, Williams is one of the best-known critics of utilitarianism (Smart and Williams 1973). To review this debate falls outside the scope of this article.
} 
In our view the character of moral progress changes when it goes beyond the robustness of a fitting place. Until then moral progress is both progress within the moral domain and, other things being equal, progress as a person as a whole. But beyond this point the danger arises that moral progress comes to overshadow other aspects of a person, aspects that may be equally important to herself or to others. It may be possible to capture some of these other aspects in a broader conception of morality - aspects like pleasantness and agreeableness, for instance - but some aspects, like creative or cognitive qualities, will fall outside of even such a broad conception. We prefer, therefore, to align our conception of individual moral progress more closely with a more general notion of becoming a better person. We therefore conceive of it in terms of the integration and increasing robustness of the moral aspect of a person's identity, in which it comes to occupy a fitting place. This is not meant to suggest that this type of progress should necessarily be rated above the other type, in which morality comes to occupy a more central place in a person's identity. Whether the latter is a good thing overall depends on a person's other qualities and traits that codetermine what fits her (a second objective criterion). It also depends on a person's own experience and her own perception of what is fitting for her - and that is the subjective criterion.

\section{The Moral Progress of Children and of Adults}

There is no reason for serious scepticism about the notion of individual moral progress. Not only is it a coherent notion, but both everyday experience and empirical research also strongly suggest that individual moral progress is possible and occurs regularly. In fact, children's moral development seems to offer strong support for the notion of moral progress, and moral education seems to be predicated on the possibility of making progress in this area. Unless the idea of moral education is incoherent or illusory, strong moral relativism or scepticism is untenable. For surely, the moral judgement of an eighteen-yearold is, on average, more adequate than that of a toddler. And we would be in a bad state if our moral sensitivity and empathic abilities did not progress beyond infancy. In short, moral development is real.

Yet we do not normally speak of children's moral development in terms of 'moral progress'. Likewise, we do not say that a child who has developed 'normally' in the moral domain has become a 'better person' (even if we confine 'better' to its moral sense). We implicitly use age-appropriate standards. An egocentric toddler is not a bad person; an egocentric adult is (to some extent, at least). At least until someone has reached a 'mature' equilibrium - and thus has 'completed' the cognitive, emotional, social, and moral development considered normal for children and adolescents - we speak of moral development only, and it would seem out of place to speak of moral progress.

This is different for adults. It is not that in the case of adults we commonly speak of moral progress - and it is quite normal to say that moral development continues throughout adulthood - but it does not strike us as odd to speak of moral progress here, nor to say that someone has become a better person (even in the moral sense of 'better' alone). In adulthood moral progress is also a real possibility, as many people will know from their own experience. But here progress is hard-won, in what can easily feel like an uphill battle. For adults, moral progress is a project: it may require tremendous effort to push the stone up the hill to the next stable position. Such a position, in this image, signifies that certain ways of thinking, feeling, and acting have become habitual; and because to change bad habits and develop good ones is 
difficult, moral progress in adulthood tends to be slow (if it occurs at all). And perhaps the image of ridges on the slope, of stable positions, is actually too optimistic if it suggests that maintenance is not needed to sustain our good habits. They may be dislodged not just by positive force, but also through laziness and inaction.

To some extent this is true for children, too, but in their case habits will be less deeply ingrained, and furthermore, there are always others pushing their stone uphill. Parents and to a lesser extent other educators are responsible for the moral development of children, and can be held to account if they do not fulfil their role. Moreover, the process of socialization and the demands of interacting with peers take children's moral development in their wake. We noted in 2.1 that progress need not be the result of intentional effort, and that it rarely is in the case of young children. Yet we cannot truly speak of moral progress until the child comes to 'own' it; in that sense moral progress is never something that merely happens to someone - there is always some (not necessarily conscious or explicit) 'activity' on the part of the 'subject of progress' required in order to make it actual progress. Still, children's progress is strongly driven by factors other than their own striving. For adults, despite the many forms of invisible support a society provides for people's moral functioning, the moral progress they make is largely up to them. It is also much more a matter of refining sensitivities, strengthening commitments and virtues, and deepening understanding (among others of the 'semantic depth' of our concepts, as Moody-Adams suggested), than of making developmental leaps. Once you have become capable of 'empathy beyond the situation' (Hoffman), for instance, progress lies in the consistency and fullness with which you use this capacity.

\section{Concluding Remarks}

In this article we have drawn several conclusions with regard to moral progress. These can be summarised in the following points. We have argued that: moral progress is a coherent notion; moral progress should be conceived of as development that is evaluated positively on the basis of relatively stable moral criteria that are the fruit and the subject of an ongoing conversation; moral progress does not imply the idea of an end-state; individual moral progress is best conceived of as the development of various components of moral functioning and their robust integration in a person's identity; both children and adults can progress morally - even though we would probably not speak in terms of progress in the case of children - but adults' moral progress is both more hard-won and to a greater extent a personal project rather than a collective effort.

As said, our considerations here are largely formal. An interesting possibility, however, is that of substantive moral progress through the improvement of moral views, or the principles adhered to. This might even take the form of a conversion. Both children and adults can 'progress' in this way. Someone who develops away from racism or bigotry makes moral progress. This will involve changes, not just in the cognitive realm, but likely in all aspects of moral functioning. Especially when it comes to substantive notions and criteria of moral progress people will differ about what counts as progress. This is no reason to drop the notion, however, but all the more reason to continue the conversation.

Acknowledgments We thank two anonymous reviewers for their helpful, constructive comments on the first version of this article. 
Open Access This article is distributed under the terms of the Creative Commons Attribution 4.0 International License (http://creativecommons.org/licenses/by/4.0/), which permits unrestricted use, distribution, and reproduction in any medium, provided you give appropriate credit to the original author(s) and the source, provide a link to the Creative Commons license, and indicate if changes were made.

\section{References}

Baillargeon R et al. (2014) Infant social cognition: psychological and sociomoral reasoning. In: Gazzaniga MS, Mangun GR (eds) The cognitive neurosciences. MIT Press, Cambridge (MA), p. 714

Benozio A, Diesendruck G (2015) Parochialism in preschool boys' resource allocation. Evol Hum Behav 36 : 256-264

Bergman R (2002) Why be moral? A conceptual model from developmental psychology. Hum Dev 45:104-124

Blasi A (1984) Moral identity: its role in moral functioning. In: Kurtines WM, Gewirtz JL (eds) Morality, moral behavior, and moral development. John Wiley, New York, pp. 129-139

Blasi A (1993) The development of identity: some implications for moral functioning. In: Noam GG, Wren TE, Nunner-Winkler G, Edelstein E (eds) Studies in contemporary German thought. MIT Press, Cambridge (MA), pp. 99-122

Bury JB (1987) [1932] The idea of progress: An inquiry into its origin and growth. Dover Publications, Mineola (NY)

Carr D, Steutel J (eds) (1999) Virtue ethics and moral education. Routledge, London

Colby A, Damon W (1992) Some do care. Contemporary lives of moral commitment. The Free Press, New York

Diesendruck G, Benozio A (2015) Prosocial behaviour towards ingroup and outgroup members. Encyclopedia on Early Childhood Development, http://www.child-encyclopedia.com/prosocial-behaviour/accordingexperts/prosocial-behaviour-towards-ingroup-and-outgroup-members (accessed 09-05-2016)

Eisenberg N (1992) The caring child. Harvard University Press, Cambridge (MA)

Gibbs J (2014) Moral development and reality: Beyond the theories of Kohlberg, Hoffman, and Haidt. Oxford University Press, Oxford

Godlovitch S (1998) Morally we roll along: (optimistic) reflections on moral progress. J Appl Philos 15(3):271-286

Hardy SA, Carlo G (2005) Identity as a source of moral motivation. Hum Dev 48(4):232-256

Hare RM (1952) The language of morals. Clarendon Press, Oxford

Hare RM (1981) Moral Thinking: Its Levels, Method, and Point. Clarendon Press, Oxford

Hoffman M (2000) Empathy and moral development. Cambridge University Press, Cambridge

Jamieson D (2002) Is there progress in morality? Utilitas 14(3):318-338

Kagan J (2008) Morality and its development. In: Sinnott-Armstrong W (ed) Moral psychology, Vol. 3: The neuroscience of morality: Emotion, brain disorders, and development. MIT Press, Cambridge (MA), pp. 297-312

Kochanska G, Aksan N (2006) Children' conscience and self-regulation. J Pers 74(6):1587-1618

Kohlberg L (1984) Essays on moral development, Vol. 2: The psychology of moral development. Harper \& Row, San Francisco

Lapsley DK (1996) Moral psychology. Westview Press, Boulder (CO)

Lapsley DK (2008) Moral self-identity as the aim of education. In: Nucci LP, Narvaez D (eds) Handbook of moral and character education. Routledge, New York, pp. 30-52

Macklin R (1977) Moral progress. Ethics 87(4):370-382

Marples R (2014) Art, knowledge, and moral understanding. Paper presented at PESGB Dutch-Flemish branch seminar, Vrije Universiteit Amsterdam

Matsuba MK, Walker LJ (2005) Young adult moral exemplars: the making of self through stories. J Res Adolesc 15(3):275-297

Moody-Adams MM (1999) The idea of moral progress. Metaphilosophy 30(3):168-185

Nisbet R (1980) History of the idea of progress. Basic Books, New York

Nucci L, Turiel E (2009) Capturing the complexity of moral development and education. Mind, Brain and Education 3(3):151-159

Peterson C (2006) A primer in positive psychology. Oxford University Press, Oxford

Platts M (1988) Moral realism. In: Sayre-McCord G (ed) Essays on moral realism. Cornell University Press, Ithaca (N.Y.), pp. 282-300

Railton P (1986) Moral realism. Philos Rev 95:163-207 
Rorty AO, Wong D (1993) Aspects of identity and agency. In: Flanagan O, Rorty AO (eds) Identity, Character and Morality. Essays in Moral Psychology. MIT Press, Cambridge, pp. 19-36

Roth A (2012) Ethical progress as problem-solving. J Polit Philos 20(4):384-406

Taylor C (1989) Sources of the self: The making of modern identity. Harvard University Press, Cambridge (MA)

Sanderse W (2012) Character education. A neo-Aristotelian approach to the philosophy, psychology and education of virtue. Eburon, Delft

Sen A (2009) The idea of justice. Allen Lane, London

Shafer-Landau R (2005) Moral realism: A defence. Clarendon Press, Oxford

Singer P (1972) Famine, affluence, and morality. Philos Public Aff 1(3):229-243

Smart JJC, Williams B (1973) Utilitarianism: For and Against. Cambridge University Press, Cambridge

Sturgeon N (1985) Moral explanations. In: Copp D, Zimmerman D (eds) Morality, Reason, and Truth. Totowa (NJ), Rowman and Allanheld, pp. 49-78

Van Doren C (1967) The idea of progress. Frederick A, Praeger, New York

Van Tongeren P (1994) Moral philosophy as a hermeneutics of moral experience. International Philosophical Quarterly Vol. XXXIV, 134(2):199-214

Weischedel W (1967) Philosophische Grenzgänge: Vorträge und Essays. W. Kohlhammer Verlag, Stuttgart

Williams B (1981) Moral luck. Cambridge University Press, Cambridge

Williams B (1985) Ethics and the limits of philosophy. Fontana, London

Wilson C (2010) Moral progress without moral realism. Philos Pap 39(1):97-116 